\title{
Tipologia de cluster no abate e preparo da carne de frango: um estudo no Estado do Paraná
}

\author{
Jefferson Andronio Ramundo Staduto \\ Universidade Estadual do Oeste do Paraná \\ Sandra Regina da Silva Pinela \\ Universidade Tecnológica Federal do Paraná \\ Ednilse Maria Willers \\ Universidade Estadual do Oeste do Paraná
}

\section{Resumo}

O Paraná é destaque nas exportações de proteína do frango do Brasil. Compreender a dinâmica existente no setor pode servir de apoio aos tomadores de decisões em estratégias para o desenvolvimento regional. Por isso, este artigo tem como objetivo identificar o tipo de aglomeração industrial da atividade de abate e preparo da carne de frango no Paraná. Para tanto, foram levantados os dados do emprego durante o período de 2006 a 2014, calculados o Quociente Locacional e o Coeficiente Gini Locacional, para encontrar a especialização do emprego na atividade, em que se destacou a região sudoeste do Estado. Complementarmente, foram analisados alguns elementos da aglomeração industrial e o resultado mostrou características de economias externas locais e ação conjunta entre os atores, configurando uma eficiência coletiva na atividade, além de outros aspectos de relação interfirmas, que enquadra a atividade da região sudoeste na tipologia de cluster Radial do tipo transnacional.

Palavras-chave: Tipologia de Cluster. Aglomerações Produtivas. Eficiência Coletiva.

\section{Cluster typology in theslaughter and preparation of the chicken meat: a study in the}

\section{State of Paraná}

\begin{abstract}
Parana state stands out in exports of chicken protein in Brazil. Understanding the dynamics in the sector can provide support to decision makers on strategies for regional development. Therefore, this article aims to identify the type of industrial agglomeration of the slaughter activity and preparation of chicken meat in Parana state. To this end, employment data was collected for the period between 2006 and 2014, the Location Quotient and the Locational Gini coefficient Locational were calculated to find the specialization of jobs in the activity, in which the southwest region of the state stood out. In addition, the characteristics of industrial agglomeration were analyzed and the result
\end{abstract}


showed characteristics of local external economies and joint action among the actors, setting up a collective efficiency in the activity, as well as other aspects of intercompany relationship that fits the activity of the southwest region in typology of transnational radial cluster.

Keywords: Cluster Typology. Productive Agglomerations. Collective Efficiency.

\section{Tipología de clúster en el abate y preparo de la carne de frango: un estudio en el Estado del Paraná}

\section{Resumen}

El Paraná es destaque en las exportaciones de proteína del pollo de Brasil. Comprender la dinámica existente en el sector puede servir de apoyo a los tomadores de decisiones en estrategias para el desarrollo regional. Por eso, este artículo tiene como objetivo identificar el tipo de aglomeración industrial de la actividad de abate y preparación de la carne de pollo en el Paraná. Para tanto, se levantaron los datos del empleo durante el período de 2006 a 2014, calculados el Cociente Locacional (CL) y el Cociente Gini Locacional (GL) para encontrar la especialización del empleo en la actividad, en la que se destacó la región Suroeste del estado. Complementariamente, se analizaron algunos elementos de la aglomeración industrial y el resultado mostró características de economías externas locales y acción conjunta entre los actores, configurando una eficiencia colectiva en la actividad, además de otros aspectos de relación interfirmas, que enmarca la actividad de la región Sudoeste en la tipología de la Clúster Radial del tipo transnacional.

Palabras clave: Tipología de clúster. Aglomeraciones Productivas. Eficiencia Colectiva.

\section{INTRODUÇÃO}

Desde a década de 1980, o setor de avicultura brasileiro tem apresentado uma evolução em sua estrutura, a qual envolve a integração a partir do cultivo de grãos para a produção de ração animal até o melhoramento genético da ave. Isso implica em seus agentes estarem inseridos numa cadeia produtiva demandante de escala e inovações tecnológicas (PAULA e FILHO, 2003; BELUSSO e HESPANHOL, 2010).

Devido à disseminação do consumo da carne de frango para diversos consumidores - internos e externos ao País -, este produto é considerado um dos mais importantes para o desempenho positivo da balança comercial brasileira. De acordo com o Ministério do Desenvolvimento/Secretaria de Comércio Exterior $\mathrm{MD} / \mathrm{SCE}$ (2014), a carne de frango figura na $6^{\mathrm{a}}$ posição entre as principais mercadorias de exportação do País, com a participação de 3,06\% do total no período de janeiro a dezembro de 2014.

Alguns fatores promoveram transformações no setor, como a abertura da economia brasileira ao comércio internacional no início da década de 1990, a estabilização econômica por meio do controle da inflação a partir do Plano Real (1994) e as mudanças tecnológicas inseridas ao longo da cadeia. De tal ordem, que impactou na reorganização do processo produtivo e na busca por maior eficiência, quer seja no aumento da produtividade ou na qualidade do produto.

As novas configurações encontradas na base produtiva do Estado do Paraná, principalmente as agroindústrias, representam um fator de sustentação de 
grande parte das atividades econômicas no interior do Estado, orientadas para a produção de bens mais elaborados, condizentes com a qualidade e a estratégia das grandes indústrias de alimentos (IPARDES, 2003; STADUTO, et al., 2008).

Em estudo anterior, Pinela Dalmás, Staduto e Willers (2007) constataram que o aglomerado de indústrias de abate e preparo da carne de frango no interior do Estado do Paraná reunia uma série de características para ser considerado um cluster produtivo. Para os autores supracitados, a Mesorregião Oeste paranaense se destacava na geração de empregos na atividade, em relação ao desempenho do Estado e ao nacional.

A partir das colocações acima expostas, torna-se importante reavaliar a evolução do setor nos últimos anos e identificar as características das aglomerações, no sentido de oferecer elementos de apoio à tomada de decisão sobre o desenvolvimento regional. Nesse sentido, este estudo tem como objetivo identificar o tipo de aglomeração industrial da atividade de abate e preparo da carne de frango no Paraná.

Para atingir esse objetivo, serão levantadas as variáveis do emprego referente à atividade nas regiões paranaenses, calculados o Quociente Locacional QL e o coeficiente de Gini Locacional - GL para determinar o grau de concentração e especialização do emprego.

Para tanto, o estudo foi organizado em cinco seções, além dessa introdução. Na seção dois, os procedimentos metodológicos são descritos e, na três, faz-se uma breve revisão da literatura sobre tipologias de clusters e se apresenta os dados sobre o abate e preparo da carne de frango no Paraná. Na seção quatro, o perfil da atividade produtiva é discutido, em que puderam ser apontadas as evidências empíricas do tipo de aglomeração existente. Na última seção são colocadas as considerações finais.

\section{PROCEDIMENTOS METODOLÓGICOS}

Para identificar as potenciais aglomerações produtivas na atividade de abate e preparo da carne de frango no Paraná, foram levantados os dados da produção e comparados com os demais estados do Brasil. O recorte temporal foi de 2006 a 2014, disponibilizados pela União Brasileira de Avicultura - Ubabef, pelo Sindicato e Associação dos Abatedouros e Produtores Avícolas do Paraná - Sindiavipar e pela Secretaria de Estado da Agricultura e do Abastecimento, Departamento de Economia Rural - SEAB/DERAL.

Complementarmente, o número de vínculos ativos na atividade foi levantado por meio da base de dados da Relação Anual de Informações Sociais / Ministério do Trabalho e Emprego - RAIS/MTE. Conforme Suzigan et al. (2004), a principal vantagem dessa base de dados é a elevada desagregação setorial e geográfica dos dados, o que torna possível elaborar os índices de concentração geográfica de determinada indústria e o de especialização do setor em um determinado território. No entanto, Suzigan et al. (2004) advertem que uma das limitações da RAIS/MTE é estar baseada apenas nas relações contratuais formais. Para este estudo, isso não foi considerado uma restrição para a análise.

Com o propósito de identificar a concentração geográfica da atividade, escolheu-se calcular o índice $G L$ e, para delimitar as aglomerações de empresas, com 
o apontamento das características principais referentes à estrutura industrial local, ou seja, a especialização produtiva na microrregião, foi calculado o QL. Rissete, Macedo e Meiners (2003) argumentam que essa metodologia permite identificar a aglomeração de firmas em uma mesma classe de atividade, ou afins, porém sem precisar o comércio interfirmas, que dependeria de um referencial de dados de nível municipal mais adequado, como as matrizes insumo-produto ou de relações interindustriais.

O procedimento para a determinação do QL é apresentado por Haddad (1989) como a comparação da participação percentual de uma região em um setor particular com a participação percentual da mesma região no emprego da economia nacional, estimado a partir da equação 01.

$$
Q L_{i j}=\frac{\frac{E_{i j}}{\sum_{i=1}^{n} E_{i j}}}{\frac{\sum_{j=1}^{m} E_{i j}}{\sum_{j=1}^{m} \sum_{i=1}^{n} E_{i j}}}
$$

sendo,

$Q L_{i j}=$ Quociente locacional do setor $i$ na região $j$

$E_{i j}=$ Emprego no setor $i$ da região $j$, em que $i=1,2,3, \ldots, n$ e $j=1,2,3, \ldots, m$.

$\sum_{i=1}^{n} E_{i j}=$ Emprego em todos os setores da região j;

$\sum_{j=1}^{m} E_{i j}=$ Emprego no setor $i$ de todas as regiões;

$\sum_{j=1}^{m} \sum_{i=1}^{n} E_{i j}=$ Emprego em todos os setores de todas as regiões;

Segundo Delgado e Goldinho (2002), o padrão de concentração estabelecido pelo QL denota a especialização do emprego na economia local ou regional. Para os autores, no caso do $Q L_{i j}>1$, a atividade i está relativamente concentrada na região $j$, no sentido em que esta detém na atividade $i$ uma importância mais que proporcional do que possui no espaço de referência, ou seja, a atividade i está sobre-representada na região $j$.

Se $Q L_{i j}<1$, a atividade i não está relativamente concentrada na região j, no sentido em que a unidade territorial detém na atividade $i$ uma importância relativa inferior a que detém no espaço de referência (DELGADO e GOLDINHO, 2002).

Complementarmente ao QL, um indicador do grau de concentração geográfica de uma determinada indústria em um território pode ser calculado pelo coeficiente GL, que, de acordo com Krugman (1991) e Audretsch e Feldman (1996), apresenta valores que variam de zero a um: quanto mais uma indústria for concentrada na região, estado ou país, mais próximo da unidade estará o índice e, ao contrário, quanto mais uniformemente dispersa, mais próximo de zero estará.

Suzigan et al. (2004) descrevem o procedimento do cálculo do GL, pelo qual é necessário ordenar os estados (ou regiões) de forma decrescente de índice de especialização ou QL a partir de uma variável escolhida, que, neste estudo, foi adotado o emprego formal (vínculos ativos da RAIS/MTE). A partir daí pôde ser construída a curva de localização (ou curva de Lorenz) para o setor de abate de frango do Paraná em relação ao Brasil e, posteriormente, para a Mesorregião Sudoeste em relação ao Paraná, sendo definido cada um dos eixos da seguinte forma: 
a) no eixo vertical, as porcentagens acumuladas da variável emprego no setor de abate de frango por estado ou por mesorregião.

b) No eixo horizontal, as porcentagens acumuladas da mesma variável para o total dos setores de abate de frango por estado ou mesorregião.

Em relação ao GL, segundo Suzigan et al. (2004), por definição ele consiste na relação entre a área de concentração indicada por $\alpha$ e a área do triângulo formado pela reta de perfeita igualdade com o eixo das ordenadas e com a reta $y=$ 1. Significando que $G L=\alpha / 0,5=2 \alpha$; uma vez que $0 \leq \alpha \leq 0,5$, tem-se $0 \leq G L \leq 1$. Dessa forma, quanto mais próximo de 1 (um), mais concentrado territorialmente é o setor, e vice-versa.

Conforme mencionado anteriormente, a variável-base utilizada foi o emprego ou vínculos ativos por setor de atividade, com a qual foi calculado o QL, descrevendo o padrão de comportamento dos ramos de atividades e/ou setores produtivo no espaço econômico em análise.

A partir da verificação dos dados do emprego, do cálculo do QL e do GL, poderá ser identificado o tipo de estrutura produtiva, se há presença de aglomerações e sua capacidade de promover a formação de aglomeração no setor de abate e preparo de frangos.

\section{AGLOMERAÇÕES PRODUTIVAS: CARACTERIZAÇÃO E TIPOLOGIA}

A partir da década de 1990, o processo de integração comercial entre os países incentivou uma maior mobilidade de produtos e recursos. Esse processo provoca o aumento da competição internacional e pressiona os setores produtivos a buscar novas formas de organização para a produção. Parte do entendimento dos determinantes desse desempenho econômico adveio das vantagens competitivas geradas pelas economias de aglomerações, preconizadas a partir da década de 1930.

Para Suzigan et al. (2004), as aglomerações de empresas têm como característica essencial a capacidade de gerar economias externas, incidentais ou deliberadamente criadas. Tais aglomerações contribuem para o incremento da competitividade das empresas e, em consequência, do sistema ou arranjo local geral. As economias externas podem ser incidentais, decorrentes de: a) existência de um vasto contingente de mão de obra especializada e com habilidades específicas ao sistema local; b) presença e atração de um conjunto de fornecedores especializados de matéria-prima, componentes e serviços; e, c) grande disseminação dos conhecimentos, habilidades e informações concernentes ao ramo de atividade dos produtores locais. Por outro lado, podem advir de ações conjuntas deliberadas, como a compra de matérias-primas, a promoção de cursos de capacitação gerencial e formação profissional, a criação de consórcios de exportação, a contratação de serviços especializados, o estabelecimento de centros tecnológicos de uso coletivo, entre outros.

O autor reafirma que a conjugação das economias externas incidentais com as obtidas por ações conjuntas deliberadas resulta na chamada eficiência coletiva, principal determinante da capacidade competitiva das empresas locais. Essas aglomerações produtivas podem evoluir e alcançar o status de clusters ou sistemas de produção local, como evidenciam os trabalhos de Schmitz (1997) e Igliori (2001). 
A análise sobre o perfil dos clusters em determinadas regiões permite entender o grau de eficiência coletiva e de competição em mercados internacionais, tanto das empresas de países em desenvolvimento quanto aquelas dos países desenvolvidos (Igliori, 2001).

Abordagens recentes destacam a importância da concentração espacial e setorial para a formação de economias externas e de complementaridades estratégicas, principalmente em períodos de crise. As economias externas locais e as ações conjuntas das empresas fazem parte do conceito de eficiência coletiva preconizado por Schmitz (1997). Para o autor, sem a eficiência coletiva, poucas são as chances de uma determinada aglomeração produtiva se tornar um cluster, até porque a simples ocorrência dele não é sinônimo de ganhos econômicos.

Segundo Porter (1986), os ganhos econômicos dizem respeito à vantagem competitiva, alcançada por estratégias influenciadas por forças da rivalidade entre as empresas do setor, da ameaça de novos entrantes e substitutos, do poder de barganha dos fornecedores e compradores.

Contrapondo o argumento de Porter (1986), Schmitz (1997) entende que os clusters podem alcançar ganhos econômicos por algumas situações que emergem das ações conjuntas entre os produtores locais, pelas quais ocorre a cooperação entre firmas individuais ou entre grupos delas, por meio de associações e consórcios.

Schmitz (1997) também acrescenta, como resultado da formação dos clusters, a divisão de trabalho e a especialização, pelas quais surgem trabalhadores com habilidades específicas para o setor. Além disso, as aglomerações produtivas estimulam o surgimento de fornecedores de matérias-primas, equipamentos, peças de reposição, serviços especializados e os agentes comerciais, que levam os produtos para mercados distantes.

Sob essa perspectiva, Ferrera de Lima (2011) explica que, apesar da presença de clusters territoriais não ser suficiente para estimular o desenvolvimento socioeconômico, decisivamente fortalece a cooperação entre os agentes por meio do aproveitamento de oportunidades, criação de sinergias entre os empreendedores, instituições e a sociedade.

A cooperação pode levar ao que Porter (1986) considera necessário para as empresas alcançarem uma posição no setor que permite a elas exercerem influência ou se defenderem com maior eficácia.

Para Ferrera de Lima (2011), a atração de novos empreendimentos envolve a formação de clusters territoriais, que exige sinergias para a construção de um ambiente inovativo. Nesse contexto, o autor supracitado afirma que a cooperação entre empresas e instituições é um fator-chave de estímulo para a sinergia criativa, que envolve desde a aprendizagem coletiva até a promoção de políticas.

\section{TIPOLOGIAS DE CLUSTERS}

Num sentido mais abrangente, cluster pode ser definido como uma concentração local de certas atividades econômicas. Num sentido mais restrito, está relacionado a uma variedade de aglomerações, desde as mais simples, não articuladas, às conectadas por meio de redes de empresas. É por meio disso que se desenvolve uma cadeia de valores integrada aos fatores locais e a elementos 
favoráveis à geração de processos de eficiência coletiva, e destes, a ganhos de competitividade.

Segundo Rissete, Macedo e Meiners (2003), a tipologia que será apresentada neste estudo sumariza vários trabalhos feitos por diversas instituições e autores desde a década de 1990, como os publicados pela UNCTAD (1998), Mitelka e Farinelli (2000), Santos,Crocco e Lemos (2002), Stamer (2000), Altenburg e Stamer (1999) e Markusen (1995).

A partir desses estudos, as seguintes tipologias foram registradas: a) clusters informais; b) clusters organizados; c) clusters inovativos, parques e incubadoras tecnológicas; d) clusters radiais fordistas; e) clusters radiais transnacionais. O Quadro 1 expõe a síntese das características básicas de cada um deles. 
Quadro 1. Tipologia de clusters: características básicas

\begin{tabular}{|c|c|c|c|c|c|c|}
\hline ASPECTOS & CLUSTERS INFORMAIS & CLUSTERS ORGANIZADOS & CLUSTERS INOVATIVOS & $\begin{array}{l}\text { INCUBADORAS PARQUES } \\
\text { TECNOLÓGICOS }\end{array}$ & $\begin{array}{l}\text { CLUSTERS RADIAIS } \\
\text { FORDISTAS }\end{array}$ & $\begin{array}{l}\text { CLUSTERS RADIAIS } \\
\text { TRANSNACIONAIS }\end{array}$ \\
\hline Tamanho das firmas & Micro & $\begin{array}{c}\text { Pequenas, médias e } \\
\text { grandes }\end{array}$ & Pequenas, médias e grandes & Pequenas e médias & Médias e grandes & Médias e grandes \\
\hline Confiança & Baixa & Alta & Alta & Alta & Baixa & Média \\
\hline Cooperação & Baixa & Alta & Alta & Baixa & Baixa & Média a alta \\
\hline Existência de liderança & Baixa & Baixa a média & Alta & Baixa a média & Média & Média a alta \\
\hline Especialização & Baixa & Média & Alta & Média & Média & Alta \\
\hline Ligações em rede & Algumas & Algumas a muitas & Muitas (extensivas) & Baixa & Hierárquica & hierárquica \\
\hline Nível tecnológico & Baixo & Médio & Alto & Baixo a alto & Médio & Alto \\
\hline Aprendizado & Pequeno & Médio a alto & Alto (contínuo) & Alto & Médio & Médio a alto \\
\hline Mudança dos produtos & Baixa ou nenhuma & Alguma & Contínua & Alta & Alguma & Alta \\
\hline Competição & Alta & Alta & Alta & Média & Média & Média \\
\hline Mercado & Local & Regiona/nacional & Nacional/internacional & Nacional/internacional & Nacional & Nacional/internacional \\
\hline Exportação & Pouca ou nenhuma & Alguma a muita & Muita & Alguma & Alguma & Muita \\
\hline Importação & Pouca ou nenhuma & Alguma & Muita & Alguma & Alguma & Muita \\
\hline $\begin{array}{c}\text { Geração de empregos } \\
\text { diretos }\end{array}$ & Elevado & Elevado & Baixo & Baixo & Médio & Médio \\
\hline $\begin{array}{c}\text { Multiplicador regional } \\
\text { (endogenia) }\end{array}$ & Baixo & Médio & Alto & Médio a alto & Alto & médio \\
\hline
\end{tabular}

Fonte: matriz adaptada por Rissete, Macedo e Meiners (2003, p. 373). 


\section{CLUSTERS INFORMAIS}

Este tipo de aglomeração produtiva é formado por um agrupamento de microempresas que objetivam garantir a subsistência de seus proprietários. Suas principais características são: capital social modesto, grande desconfiança, concorrência danosa, mínima capacidade inovativa, produtos de tecnologia simples e reduzidas barreiras à entrada de produtos novos. Tanto a coordenação quanto o network entre firmas são frágeis.

As empresas enquadradas nessa tipologia são deficientes em termos de competências técnicas, gerenciais e comerciais. Seus empresários são pouco qualificados e apresentam elevado grau de deficiência em conhecimentos tácitos e tecnológicos. Em termos de mão de obra, há significativos problemas de analfabetismo funcional.

É comum entre as empresas de um cluster informal, a precariedade de infraestrutura, de recursos financeiros, de centros de produtividade e de programas de treinamento. Também faltam informações estratégicas, o que reforça o baixo crescimento destas empresas e a sua informalidade.

\section{CLUSTERS ORGANIZACIONAIS}

Os clusters organizacionais caracterizam-se por firmas de pequeno porte que interagem entre si por redes de produção de bens finais, pouco complexos e com escala reduzida. Orientam-se por meio de ações coletivas, que visam à provisão de infraestrutura e serviços em prol do desenvolvimento organizacional, da articulação e do planejamento estratégico. A rede de informações (network) entre as empresas deste tipo de cluster é amplamente utilizada.

Geralmente os negócios apresentam baixo grau de inovação. Estruturam-se em conhecimentos simples baseados na aprendizagem tácita e na periodicidade dos inter-relacionamentos pessoais e comunitários. Os ganhos de competitividade advêm da especialização flexível das firmas.

Segundo Porter (1998), os clusters organizacionais consolidados são concentrações geográficas de firmas inter-relacionadas. Essas firmas geralmente produzem serviços e produtos finais. Configuram-se como fornecedoras de insumos especializados, componentes, equipamentos e empresas de distribuição. Fabricam produtos complementares e correlatos. São fornecedores de infraestrutura especializada que competem e cooperam entre si.

\section{CLUSTERS INOVATIVOS}

Essa tipologia representa as aglomerações de empresas que produzem e introduzem no mercado novos produtos e atividades tecnológicas, ou seja, são empresas de base tecnológica. Para tanto, faz uso de uma intensa interação com empresas, instituições de ensino, de pesquisa e desenvolvimento (P\&D) em tecnologia. 
Essa rede de relacionamentos possibilita constantes inovações no produto, o que leva ao aperfeiçoamento e à adaptação tecnológica, necessários ao lançamento de novos produtos e processos. Assim, caracterizam-se em empresas de produção altamente flexível. Em função disso, atendem nichos de mercado, com o foco na contínua atualização tecnológica de seus produtos. Primam pela qualidade, fazendo uso de novas tecnologias de informação e com elas, introduzindo rápidas mudanças em sua linha de produção. Por essa característica, os clusters inovativos encontram espaço no mercado internacional e alcançam elevado coeficiente de exportação.

\section{TECNOPOLOS, PARQUES TECNOLÓGICOS E INCUBADORAS}

Os tecnopolos são formados por clusters de empresas de pequeno e médio porte - PMEs, localizadas num mesmo território. Do ponto de vista operacional, constituem-se de agrupamentos de empresas direcionadas à pesquisa e aos negócios interligados ao desenvolvimento científico de novos produtos, desde a pesquisa, a fabricação aos testes-piloto e a comercialização. As unidades produtivas são compostas de laboratórios dispostos em um ambiente de alta qualidade de serviços de apoio, atendidas e fomentadas por universidades e institutos de pesquisa e desenvolvimento (P\&D), públicos e privados.

Os tecnopolos, os parques tecnológicos e as incubadoras ${ }^{1}$ se configuram em instrumentos de estratégia de desenvolvimento econômico de cidades e regiões, pois induzem processos de crescimento na economia local e regional por meio da expansão de empresas de base tecnológica, propiciando o surgimento de ideias, produtos e firmas inovadoras.

\section{CLUSTERS RADIAIS}

A estrutura produtiva dos clusters radiais está dominada por uma ou poucas empresas âncoras de grande porte. Esta(s) empresa(s) âncora(s) detém(êm) alto grau de integração vertical e importantes economias de escala. Cerceadas por empresas fornecedoras, mantém estáveis relações de fornecimento por meio de contratos de médio e longo prazo, sendo que, em alguns casos, ocorre o intercâmbio de pessoal técnico-administrativo.

Uma característica específica deste cluster, é que a(s) empresa(s) âncora(s) nem sempre está(ão) localizada(s) na mesma região de seus fornecedores. Também merece destaque, a intervenção dos governos locais e regionais no sentido de promover negócios, prover a região da infraestrutura necessária à consolidação do cluster e nas formas de suprimento de fontes especializadas de recursos financeiros, de serviços tecnológicos e de apoio empresarial. 
Segundo Markunsen (1995), os clusters radiais podem ser de dois tipos: fordistas e transnacionais.

Os clusters radiais fordistas surgiram no ápice do processo de industrialização, momento em que prevaleciam sistemas de produção em massa. Segundo Stamer (2000), esse tipo de cluster se desenvolve em locais que propiciam vantagens de localização e de competência das empresas individuais. Também se configura por uma cultura de não cooperação. Essa cultura não cooperativa origina-se no modelo fordista de produção, que prevê a redução, ao máximo possível, das relações de dependência com outras empresas, principalmente de fornecedores. Diante disto, tem-se o desenvolvimento de uma estrutura econômica local, caracterizada por poucos contratos entre firmas.

Outra característica deste tipo de cluster é o foco da produção estar centrado nos mercados regional e nacional. Essa configuração é um reflexo do período de surgimento deste cluster². Como consequência, não há inserção no mercado internacional.

Os clusters radiais transnacionais surgiram entre as décadas de 1950 e 1980, como parte das estratégias das empresas transnacionais em atender novos mercados e a explorar vantagens comparativas nos países em desenvolvimento. Para essa demanda de mercado, os governos nacionais e receptores das empresas impuseram exigências no sentido da criação e desenvolvimento de fornecedores locais. Formava-se assim uma estrutura produtiva do tipo radial, dominada por uma empresa âncora transnacional e cerceada por um elevado número de fornecedores de empresas locais.

Contudo, a partir da década de 1980, as empresas passaram por novos processos de organização industrial. Capitaneada pelas novas tecnologias da informação, comunicação e da produção flexível, a produção torna-se segmentada por módulos, cuja gestão é integrada em todo seu encadeamento produtivo. Essa mudança estrutural das empresas transformou os processos sequenciais de produção em contínuos, que leva à produção de bens diferenciados.

A junção desses fatores possibilitou economias de escala associadas a economias de escopo, favorecendo a constituição de redes de empresas estruturadas hierarquicamente. Nesse contexto, os clusters radiais transnacionais se estabelecem a partir de uma empresa âncora e por uma rede de fornecedores integrados. 


\section{ABATE E PREPARO DA CARNE DE FRANGO: PERFIL DA ATIVIDADE}

Segundo a Ubabef (2014), a produção brasileira de carne de frango, em 2013, totalizou 12,3 milhões de toneladas, com um volume de consumo per capita de 41,8 quilos por habitante, por ano. Em 2005, a produção era de 9,3 milhões de toneladas e a população brasileira consumia, por ano, 35,48 quilos de carne. Em termos percentuais, no período, a produção cresceu numa média de 3,6\% ao ano e o consumo evoluiu em $2 \%$ ao ano.

Tabela 1. Produção, exportação e consumo da carne de frango no Brasil 2005-2011

\begin{tabular}{lccc}
\hline \multirow{2}{*}{ Ano } & \multicolumn{2}{c}{ Volume $(\mathrm{t})$ em milhões } & $\begin{array}{c}\text { Consumo anual } \\
\mathrm{kg} / \mathrm{hab}\end{array}$ \\
\cline { 2 - 3 } 2005 & Produção & Exportação & 35,48 \\
2006 & 8,95 & 1,846 & 35,68 \\
2007 & 8,34 & 2,718 & 37,02 \\
2008 & 10,31 & 3,287 & 38,47 \\
2009 & 10,94 & 3,646 & 38,47 \\
2010 & 10,98 & 3,635 & 44,09 \\
2011 & 12,23 & 3,820 & 47,38 \\
\hline
\end{tabular}

Fonte: UBABEF (2010 e 2012).

Em relação ao consumo, a Tabela 1 mostra que houve uma alteração significativa somente em 2010. Segundo estudo de Triches et al. (2004), a demanda por carne de frango é relativamente elástica em relação ao preço. Verificou-se que um aumento médio de $10 \%$ no preço da carne de frango reduziria o consumo per capita em aproximadamente $11 \%$, mantidos os demais preços inalterados.

Contrário a esse argumento, o Instituto de Economia Agrícola - IEA (2014), da Secretaria de Agricultura e Abastecimento do Estado de São Paulo, apontou uma variação positiva no preço de varejo da carne de frango de $25 \%$ no período de janeiro de 2007 a dezembro de 2011 e, mesmo assim, conforme a Tabela 1, o aumento do consumo foi de 33,5\%. A explicação pode estar no desempenho dos preços da carne bovina, que, no mesmo período, obteve $110 \%$ de aumento no varejo, o que torna a carne de frango um produto substituto.

Siffert Filho e Faveret Filho (1998) explicam que, na cadeia de frangos, as empresas estabeleceram um sistema de contratos com seus principais fornecedores, pelos quais foi possível obter grande capacidade de controle dos custos, assegurar previsibilidade na qualidade e quantidade de matéria-prima, alcançar rápida difusão de inovações tecnológicas, fatores que viabilizaram estratégias de diferenciação de produtos. Além disso, o surgimento de negócios para exportação favoreceu o desenvolvimento de pesquisas e novas tecnologias, o que induziu a ascensão dessa atividade na economia.

Em 2011, foram negociadas 3,95 milhões de toneladas de carne de frango brasileira no mercado internacional, que representou $40 \%$ do total das exportações mundiais e colocou o Brasil na posição de liderança. Os Estados Unidos é o segundo maior país exportador, com 2,97 milhões de toneladas do produto. Apesar desse desempenho, no período entre 2005 e 2011, houve uma queda na participação mundial dos dois países. Em 2005, a produção de carne de frango do Brasil e dos 
Estados Unidos representava 79,5\% das exportações mundiais e, em 2011, caiu para $70,5 \%$.

Segundo a Ubabef (2012), a Região Sul do Brasil concentrou mais de $50 \%$ da produção de carne de frango no período entre 2002 e 2011. O Paraná liderou o ranking dos maiores estados produtores, com a média de $24 \%$ da produção total. Santa Catarina ficou em segundo lugar, com $18 \%$ e o Rio Grande do Sul, no terceiro lugar, com $15 \%$.

Em 2014, no Paraná, estão estabelecidos 43 abatedouros associados ao Sindiavipar, que é uma entidade fundada em 1992 para representar as empresas do setor no mercado interno e externo. Dos associados, quatorze comercializam produtos com a União Europeia (32\%), sete exportam para a China (16\%) e oito unidades não estão habilitadas a exportar (18\%).

Além da habilitação para a exportação, alguns países importadores demandam especificidades no abate, o que leva 27 abatedouros a se adequarem para atender aos procedimentos do ritual mulçumano denominado Halal, o qual implica uma configuração física especial do frigorífico. Devido à atividade não possuir demanda interna suficiente para o volume ofertado, é necessário exportar seus produtos para outros estados e mercado internacional, o que significa importante procura pela habilitação no Serviço de Inspeção Federal (Sindiavipar, 2015).

De acordo com o DERAL (2014), da SEAB do Paraná, o frango de corte figura como o segundo maior Valor Bruto de Produção -

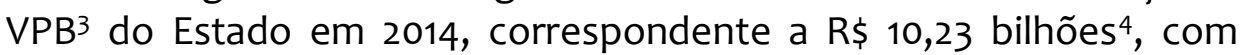
aumento de $2 \%$ em valor e quantidade produzida. Mesmo o crescimento ser considerado moderado, a demanda no setor oferece condições favoráveis para maiores investimentos.

A dinâmica do setor é favorável e se manteve nos últimos anos. Além disso, a geração de emprego que a atividade promove também continua sendo significativa no contexto econômico e sua evolução será demonstrada na próxima seção. Esse comportamento evidencia a importância da atividade na economia regional, estadual e nacional.

\section{A GERAÇÃO DE EMPREGOS NA ATIVIDADE DE ABATE DE FRANGOS}

O desempenho na geração de emprego da atividade econômica "Abate de aves e outros pequenos animais e preparação de produtos de carne ${ }^{5 ",}$ no período entre 2006 a 2014, é apresentado na Tabela 2, na qual os dados foram estratificados pelos resultados alcançados em nível nacional, na Região Sul e nos respectivos estados que a compõe.
3 O VPB é calculado pela multiplicação da produção primária do estado pelo valor médio dos produtos e tem a participação de $8 \%$ na composição dos índices do Fundo de Participação dos Municípios - FPM, no Imposto sobre Circulação de Mercadorias Prestação de Serviços ICMS arrecadados.

4 Equivalente a US\$ 27,23 bilhões, baseado na taxa de câmbio da moeda norte americana referente ao dia $31 / 12 / 2014$, igual a $\mathrm{R} \$$ 2,662 .

5 Pela Classificação Nacional de Atividade Econômica - CNAE 95, da RAIS, do MTE. 
Tabela 2. Vínculo ativo na atividade de abate e preparo de aves e outros pequenos animais, Brasil e Região Sul, 2006 a 2014

\begin{tabular}{cccccc}
\hline ANO & BRASIL & REGIÃO SUL & RS & SC & PR \\
\hline 2006 & 146.254 & 90.095 & 25.439 & 33.307 & 31.349 \\
2007 & 165.804 & 104.546 & 27.143 & 38.801 & 38.602 \\
2008 & 149.106 & 93.921 & 24.007 & 28.780 & 41.134 \\
2009 & 150.460 & 92.826 & 25.605 & 25.070 & 42.151 \\
2010 & 154.789 & 92.993 & 24.274 & 25.610 & 43.109 \\
2011 & 162.899 & 93.215 & 24.332 & 26.698 & 42.185 \\
2012 & 143.001 & 79.165 & 22.764 & 18.928 & 37.473 \\
2013 & 164.503 & 98.958 & 23.263 & 25.862 & 49.833 \\
2014 & 177.850 & 107.848 & 25.829 & 24.890 & 57.129 \\
\hline Total & 1.414 .666 & 853.567 & 222.656 & 247.946 & 382.965 \\
\hline
\end{tabular}

Fonte: Ministério do Trabalho e Emprego/RAIS (2015).

Baseado nos dados da Tabela 2, a Região Sul participa com 60\% do total dos vínculos ativos computados no Brasil, e o Paraná obteve o maior índice entre os estados do Sul, com 27\% de participação, seguido pelo Estado de Santa Catarina, que representou $18 \%$ do total dos vínculos.

No período analisado, são verificadas quedas significativas em relação aos vínculos de trabalho na atividade. Em 2008, a perda de desempenho nacional foi em torno de $10 \%$ e o mesmo ocorreu com o total da Região Sul. No entanto, naquele ano, o Paraná apresentou um aumento de 6,5\% nos vínculos ativos e Santa Catarina, uma perda mais significativa, com $26 \%$ de queda. Em 2012, os três estados sofreram perdas de vínculos na atividade, que também ocorre em âmbito nacional em torno de $12 \%$, mas Santa Catarina apresentou uma queda de $29 \%$.

Em períodos mais recentes, como em 2014, o emprego no abate e preparo de aves e outros pequenos animais cresceu em relação aos anos anteriores, principalmente se comparado com o ano de 2006, cujo valor aumentou em $22 \%$. 0 Rio Grande do Sul apresentou uma elevação de $2 \%$ e o Paraná se destacou com $82 \%$ de variação positiva no período. Por outro lado, Santa Catarina apresentou uma queda de $25 \%$.

A perda de desempenho no ano de 2008 deve ter sido em decorrência da crise internacional no período, que, segundo Pochmann (2009), provocou uma inflexão na trajetória de expansão socioeconômica nacional, cujos principais impactos se deram no mercado de trabalho. De acordo com Mani, Meneses-Filho e Komatsu (2017), isso ocorre devido ao baixo nível de investimento que diminui a geração de empregos.

Mani, Meneses-Filho e Komatsu (2017) consideram que, apesar do Brasil passar por um período mais crítico de recessão econômica, que foi a crise de 2014, em 2012, a economia já apresentava perda de desempenho, o que também explica a redução dos vínculos ativos naquele ano. De acordo com a Ubabef (2013), as causas de queda na produção em 2012 podem ser explicadas pela alta dos preços dos principais insumos, como o milho e a soja. Também, a ausência de créditos para os avicultores e agroindústrias resultou em paralisação das atividades de diversas unidades produtivas, o que implica em demissões dos trabalhadores.

Embora a crise econômica tenha afetado o setor, os resultados aqui apresentados apontam a liderança do Paraná, considerados os estados da Região 
Sul. As plantas de abate e preparo de aves e pequenos animais estão localizadas em diversas regiões de forte dinâmica econômica no Estado.

A Tabela 3 descreve os valores dos vínculos ativos das regiões do Paraná, delimitadas como Mesorregióes Geográficas, conforme determina o Instituto Paranaense de Desenvolvimento Econômico e Social - Ipardes (2015). Por ela é possível observar que a Mesorregião Oeste paranaense obteve no período entre 2006 e 2014, uma participação média no total dos vínculos ativos, que representou $35 \%$ em relação ao total das regiões. A região norte central obteve o segundo lugar, com $25 \%$ e a região sudoeste em terceiro lugar, com 19,63\%. A Mesorregião NorteCentral manteve a segunda colocação na geração de emprego no Estado neste setor.

Tabela 3. Vínculos ativos na atividade de abate e preparo de aves e outros pequenos animais, nas Mesorregiões Geográficas Paranaenses - 2006 a 2014

\begin{tabular}{lrrrrrrrrrr}
\hline \multicolumn{1}{c}{ Mesorregião } & 2006 & 2007 & 2008 & 2009 & 2010 & 2011 & 2012 & 2013 & 2014 & Total \\
\hline Oeste & 11.883 & 14.297 & 14.308 & 14.846 & 14.382 & 14.827 & 14.831 & 16.791 & 18.168 & 134.333 \\
Norte Central & 6.742 & 8.646 & 9.564 & 10.521 & 10.984 & 9.210 & 10.974 & 13.132 & 16.123 & 95.896 \\
Sudoeste & 6.315 & 7.408 & 8.113 & 8.275 & 9.073 & 9.239 & 2.808 & 9.562 & 9.869 & 70.662 \\
Noroeste & 2.464 & 3.071 & 3.220 & 3.526 & 4.096 & 5.026 & 5.094 & 6.140 & 7.666 & 40.303 \\
Metropolitana de & 2.932 & 3.480 & 3.469 & 3.277 & 3.210 & 2.453 & 2.022 & 1.829 & 1.688 & 24.360 \\
Curitiba & 988 & 1.259 & 1.525 & 1.518 & 1.137 & 1.188 & 1.188 & 1.079 & 1.111 & 10.993 \\
Norte Pioneiro & 22 & 88 & 584 & 182 & 219 & 236 & 554 & 1.298 & 2.498 & 5.681 \\
Centro Ocidental & 1 & 352 & 347 & 0 & 0 & 3 & 0 & 1 & 3 & 707 \\
Centro-Sul & 0 & 0 & 1 & 4 & 4 & 3 & 2 & 1 & 3 & 18 \\
Centro Oriental & 2 & 1 & 3 & 2 & 4 & 0 & 0 & 0 & 0 & 12 \\
Sudeste & 31.349 & 38.602 & 41.134 & 42.151 & 43.109 & 42.185 & 37.473 & 49.833 & 57.129 & 382.965 \\
\multicolumn{1}{c}{ Total } & & & & & & & & & \\
\end{tabular}

Nota: o total refere-se à soma dos vínculos no período. Fonte: MTE/RAIS (2015)

De acordo com Pinela Dalmás, Staduto e Willers (2007), em período anterior a Mesorregião Oeste do Paraná havia obtido o maior crescimento do número de empregos na atividade, com a geração de 13 mil empregos, o que representava $52 \%$ em relação ao Estado.

De acordo com Ferrera de Lima, Eberhardt e Barros (2011), a maioria dos municípios do oeste do Paraná possui suas economias voltadas ao setor primário. No entanto, segundo a Ubabef (2013), em 2012, a produção de frango se retraiu devido à alta nos preços da soja e milho, o que levou ao fortalecimento do preço das principais commodities regionais e explica a Mesorregião Oeste não sentir de maneira mais intensa os reflexos das oscilações do volume de emprego, como ocorreu em outras localidades.

Diante ao exposto, é possível afirmar que a Mesorregião Oeste paranaense manteve sua liderança na produção e abate de aves e outros pequenos animais nas últimas três décadas. Porém, pode ter havido alteração referente à especialização do emprego, tendo em vista a diversificação da indústria na região. Por isso, a próxima seção irá tratar sobre esses aspectos de aglomeração. 


\section{A AGLOMERAÇÃO INDUSTRIAL DO ABATE E PREPARO DA CARNE DE FRANGO}

Pinela Dalmás, Staduto e Willers (2007) utilizaram o coeficiente de GL complementarmente ao indicador QL para identificar a existência de uma concentração industrial do setor de abates de frangos na Mesorregião Oeste paranaense no ano de 2006. Os autores observaram que, dos 27 estados brasileiros, apenas seis obtiveram $Q L>1$ na atividade de abate de aves. O Estado do Paraná obteve um QL de 3,508 e, considerando somente a Região Sul, o resultado do QL foi igual a 1,18. Os estados de Santa Catarina e do Rio Grande do Sul obtiveram um QL<1. Então, a atividade estava relativamente concentrada no Paraná, com a especialização do emprego na economia.

Em relação à análise regional, Pinela Dalmás, Staduto e Willers (2007) apontaram que a Mesorregião Oeste do Paraná havia obtido um QL de 4,36 (QL>1) e este era o mais elevado entre as demais regiões, indicando que a atividade de abate e preparo da carne de frango no Paraná estava relativamente concentrada naquela região, o que denotava a especialização do emprego na economia regional.

Pinela Dalmás, Staduto e Willers (2007) também verificaram a concentração do emprego pelo cálculo do $G L$ e os seguintes resultados foram apontados: $G L=55 \%$ do Paraná em relação aos demais estados do Brasil e $G L=64 \%$ da Mesorregião Oeste em relação às outras regiões do Paraná. Assim, existia a especialização e concentração geográfica da atividade de abate de frangos, bem como a especialização do emprego, acima do desempenho estadual e nacional.

No intuito de se verificar a manutenção dos desempenhos acima citados, indicadores GL e QL foram recalculados para o ano de 2014, conforme segue.

Tabela 4. Quociente Locacional dos estados brasileiros para a atividade de abate e preparo de aves e outros pequenos animais - 2014

(continua)

\begin{tabular}{ccccc}
\hline Estados - Brasil & Abate de Aves & Todas Atividades & QL & $a / G L$ \\
\hline Paraná & 57.129 & 3.110 .005 & 5,10 & 0,01 \\
Santa Catarina & 24.890 & 2.249 .043 & 3,07 & 0,02 \\
Mato Grosso do Sul & 6.127 & 647.451 & 2,63 & 0,01 \\
Rio Grande do Sul & 25.829 & 3.083 .350 & 2,33 & 0,04 \\
Goiás & 9.060 & 1.505 .472 & 1,67 & 0,02 \\
Tocantins & 1.552 & 274.361 & 1,57 & 0,00 \\
Mato Grosso & 2.738 & 801.792 & 0,95 & 0,01 \\
Minas Gerais & 13.516 & 5.058 .390 & 0,74 & 0,08 \\
Acre & 297 & 132.864 & 0,62 & 0,00 \\
Espírito Santo & 1.997 & 965.731 & 0,57 & 0,02 \\
Distrito Federal & 2.485 & 1.319 .343 & 0,52 & 0,02 \\
Paraíba & 1.227 & 677.953 & 0,50 & 0,01 \\
São Paulo & 20.612 & 14.090 .838 & 0,41 & 0,25 \\
Pernambuco & 2.445 & 1.766 .098 & 0,38 & 0,03 \\
Piauí & 576 & 457.154 & 0,35 & 0,01 \\
Rondônia & 466 & 373.635 & 0,35 & 0,01 \\
Bahia & 2.835 & 2.369 .748 & 0,33 & 0,05
\end{tabular}


(conclusão)

\begin{tabular}{ccccc}
\hline Estados - Brasil & Abate de Aves & Todas Atividades & QL & $\alpha / \mathrm{GL}$ \\
\hline Rio de Janeiro & 2.784 & 4.638 .596 & 0,17 & 0,09 \\
Pará & 418 & 1.147 .803 & 0,10 & 0,02 \\
Ceará & 474 & 1.551 .973 & 0,08 & 0,03 \\
Rio Grande do Norte & 165 & 631.975 & 0,07 & 0,01 \\
Sergipe & 76 & 416.947 & 0,05 & 0,01 \\
Alagoas & 59 & 514.332 & 0,03 & 0,01 \\
Maranhão & 83 & 738.743 & 0,03 & 0,01 \\
Amazonas & 9 & 642.911 & 0,00 & 0,01 \\
Roraima & 1 & 94.319 & 0,00 & 0,00 \\
Amapá & 0 & 132.833 & 0,00 & 0,00 \\
\hline Total & 177.850 & 49.393 .660 & & 0,585 \\
\hline
\end{tabular}

Fonte: Dados da pesquisa (2015).

Os dados apresentados na Tabela 4 destacam o Paraná com QL >1, no valor de 5,10, o que representa um crescimento de $45 \%$ no período de quase dez anos e indica a relativa concentração da atividade no Estado, bem como a especialização do emprego na economia paranaense.

A representação gráfica da Tabela 4 está ilustrada na Figura 1

Figura 1. Curva de Localização do setor de abate e preparo de aves e outros pequenos animais na região Sul, em relação às demais atividades no Brasil - 2014

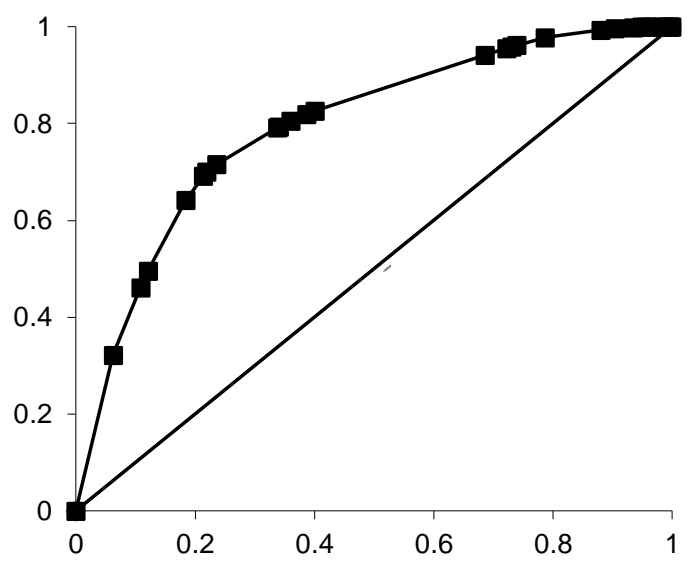

Fonte: dados da pesquisa (2015).

Complementarmente ao QL, calculou-se o GL para o Paraná em relação ao Brasil e resultou em um índice igual a 0,585 ou 59\%, o que implica numa concentração acima da média do emprego na atividade de abate e preparo da carne de frango no Paraná em relação ao Brasil.

Por continuidade, os valores do QL e GL foram calculados para as mesorregiões paranaenses e apresentados na Tabela 5. 
Tabela 5. Quociente Locacional das mesorregiões paranaenses para a atividade de abate e preparo de aves e outros pequenos animais - 2014

\begin{tabular}{ccccc}
\hline MESORREGIÕES DO PARANÁ & ABATE DE AVES & TODAS ATIVIDADES & QL & $\alpha / G L$ \\
\hline Sudoeste & 9.869 & 128.521 & 4,26 & 0,00 \\
Oeste & 18.168 & 350.411 & 2,87 & 0,04 \\
Noroeste & 7.666 & 176.196 & 2,41 & 0,03 \\
Centro Ocidental & 2.498 & 70.187 & 1,97 & 0,01 \\
Norte Central & 16.123 & 615.946 & 1,45 & 0,16 \\
Norte Pioneiro & 1.111 & 108.648 & 0,57 & 0,03 \\
Metropolitana de Curitiba & 1.688 & 1.371 .395 & 0,07 & 0,43 \\
Centro-Sul & 3 & 97.851 & 0,00 & 0,03 \\
Centro Oriental & 3 & 178.473 & 0,00 & 0,06 \\
Sudeste & 0 & 69.506 & 0,00 & 0,02 \\
\hline Total & 57.129 & 3.167 .134 & & 0,62 \\
\hline
\end{tabular}

Fonte: dados da pesquisa (2015).

A Tabela 5 demonstra que a Mesorregião Oeste perdeu desempenho na concentração da atividade nos últimos dez anos, pois, de acordo com Pinela Dalmás, Staduto e Willers (2007), em 2006, o QL era igual a 4,36 e, em 2014, resultou em 2,87. A região paranaense que ocupou a liderança em 2014 foi a Sudoeste, com um $Q L$ de 4,26. Dessa forma, tem-se que a atividade de abate e preparo da carne de frango mudou sua concentração relativa para a região sudoeste do Estado, o que implica numa maior especialização do emprego na economia da região.

Em relação à concentração do emprego na atividade, o $G L$ para as regiões do Estado do Paraná foi calculado, cujo valor foi de $62 \%$.

Figura 1. Curva de Localização do setor de abate e preparo de aves e outros pequenos animais em relação às demais atividades no Estado do Paraná - 2014

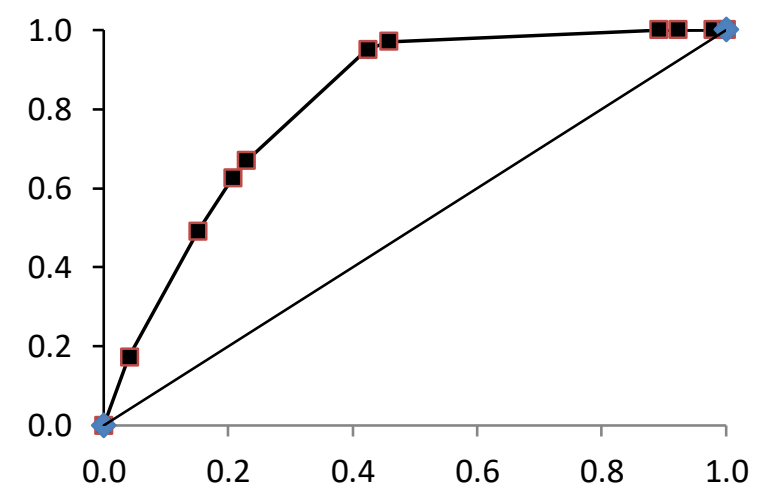

Fonte: dados da pesquisa (2015). 
O resultado do cálculo do GL indicou uma concentração acima da média do emprego, na atividade de abate e preparo da carne de aves e pequenos animais da Mesorregião Sudoeste, em relação às demais atividades, alterando os resultados encontrados por Pinela Dalmás, Staduto e Willers (2007). Isso reflete um dinamismo industrial no desenvolvimento regional, cujas principais características são discutidas a seguir.

\section{EVIDÊNCIAS EMPÍRICAS DA AGLOMERAÇÃO NA ATIVIDADE DE ABATE PREPARO DE FRANGO NA REGIÃO SUDOESTE DO PARANÁ}

Neste estudo, ficou em evidência a região sudoeste do Paraná quanto à especialização e concentração geográfica da atividade de abate e preparo de frango (aves e pequenos animais), assim como a especialização do emprego acima do desempenho estadual e nacional.

A maior parte das agroindústrias que atuam no sudoeste paranaense está habilitada à exportação, além de seguirem procedimentos específicos de produção, como é o caso do Halal, presente em $40 \%$ delas. Esse tipo de estratégia para atender às especificações dos clientes pode explicar a atração da demanda por produtos e serviços da região.

Outro aspecto a ser destacado é a existência de duas unidades operacionais de uma grande empresa, como a BRF, que além de cumprir os requisitos de exportação mencionados acima, exporta para um mercado exigente, que é a União Europeia. Isso reforça a característica de especialização no setor, pois a exposição ao comércio internacional implica na necessidade de incorporar inovações nos produtos e processos para manter o nível tecnológico nos padrões estabelecidos pelo comércio internacional e, como consequência, exige altos investimentos e alocação de recursos.

A $\mathrm{BRF}^{6}$ pode ser considerada uma empresa âncora, que atua em diversas regiões do Brasil e em territórios estrangeiros. As outras empresas são agroindústrias menores e a maioria atua configurada como cooperativa, que, juntamente com a BRF, integram produtores dedicados ao insumo do abate, o frango. A maior parte dessas empresas está associada ao Sindiavipar, na busca de maior representatividade do setor junto às políticas governamentais, além de canais facilitadores para a sua inserção no mercado externo.

A atuação dessas empresas promoveu, na economia regional, o surgimento de mão de obra especializada, com habilidades para a engorda dos frangos e produção de insumos para ração, a qual recebeu incentivos financeiros e técnicos para a instalação de aviários, a garantia de venda da produção e continuidade do negócio por meio de contratos firmados de longo prazo. A dinâmica dessas empresas promoveu a vinda de escolas técnicas e universidades, que

\footnotetext{
6 Em 2012, a empresa BRF foi instituída após processo de fusão iniciado em 2009 entre a Sadia e a Perdigão. É a sétima maior empresa de alimentos do mundo em valor de mercado e responsável por $9 \%$ da exportação mundial. Possui 47 fábricas instaladas no Brasil, sendo 34 de processamento de carnes e 11 unidades no exterior, com 104,4 mil funcionários diretos. Em 2014, abateu 1.664 milhões de cabeça de aves (BRF, 2014).
} 
elaboram projetos direcionados ao agronegócio, como é o caso do Instituto Federal e da Universidade Tecnológica Federal do Paraná.

Essas economias externas, criadas por causa das aglomerações das agroindústrias, condizem com o que a literatura define como sendo incidentais, ou seja, a existência de um volume considerável de mão de obra especializada, capaz de atender ao sistema de produção local, que atrai fornecedores especializados e promove a disseminação de conhecimento, habilidades e informações aos produtores da região.

Não obstante, pode ser verificada a existência de economias externas deliberadas, promovidas pelas agroindústrias regionais, principalmente na criação de renda e emprego gerados pela integração das atividades, que incluem os pequenos proprietários da região e gera serviços especializados para atender a contratos formalizados (cada agroindústria mantém sua integração em espaços delimitados).

Além disso, há evidências de influência dessas empresas agroindustriais nas ações de políticas públicas e privadas da região. Juntamente com os governos locais e outras organizações, as agroindústrias apoiam atividades esportivas, projetos de saúde, de instalação de empresas incubadoras para a pesquisa e desenvolvimento de novos produtos, de incentivos para os agricultores nos investimentos para a diversificação das atividades avícolas, e alocação de recursos para integração da sociedade com as escolas, entre outros. Ao mesmo tempo em que estas empresas competem, promovem ações que fortalecem suas atuações.

Na região sudoeste do Paraná estão instaladas várias empresas prestadoras de serviços e equipamentos para as agroindústrias abatedoras e avicultores (Ipardes, 2015), indicando aspectos de externalidades.

Apesar dessas características, Schmitz (1997) alerta que economias externas locais não são suficientes para explicar a força das aglomerações das firmas. O autor sugere a necessidade de conjugar esse fenômeno à ação conjunta, obtendo com isso a eficiência coletiva, ou seja, a vantagem competitiva.

A dinâmica verificada na atividade de abate e preparo da carne de frango da Mesorregião Sudoeste Paranaense apresenta características da ocorrência de inovações, em que o empresário se destaca como o agente responsável por sua introdução e disseminação.

Na região sudoeste do Paraná, a inovação foi introduzida principalmente pela BRF e imitada por outras agroindústrias locais. Contudo, elas foram imitadoras na atividade, mas inovaram na forma de se organizar, concebendo o sistema cooperativado, que, segundo o Ipardes (2015), é uma particularidade do Estado do Paraná, o que pode refletir certo grau de amadurecimento em busca da ação coletiva.

O desenvolvimento da região sudoeste paranaense não ocorre de forma contínua, conforme mostra o índice QL, que apresentou oscilações durante o período de análise, demonstrando situações de crescimento e de arrefecimento da produção.

A constatação da concentração no setor de abate e preparo da carne de frango na região, com a presença de especialização e componentes da eficiência coletiva, corrobora o que é apresentado na literatura para caracterizá-la como um cluster produtivo, mas com a necessidade de ser especificada uma descrição. Por 
isso, no Quadro 2, são descritas algumas características da aglomeração produtiva dessa região, constituídas a partir dos tipos de clusters sugeridos por Rissete, Macedo e Meiners (2003), Markunsen (1995), e dos fatores de economias externas apresentados por Suzigan et al. (2004).

\section{Quadro 2. Principais características de aglomeração produtiva no sudeste do}

Paraná

\begin{tabular}{|c|c|}
\hline Fator & Descrição \\
\hline $\begin{array}{l}\text { Perfil industrial } \\
\text { regional }\end{array}$ & $\begin{array}{l}\text { A presença de perfil industrial de grande porte, com domínio e liderança de } \\
\text { empresa âncora (BRF), que atua em diversas regiões do país e territórios } \\
\text { estrangeiros (transnacional). De acordo com o Sindiavipar (2015), a maior } \\
\text { parte das outras empresas são agroindústrias cooperativadas que também } \\
\text { integram produtores, principalmente os de pequeno porte, para o } \\
\text { fornecimento do frango em condições de abate. }\end{array}$ \\
\hline Relações interfirmas & $\begin{array}{l}\text { A empresa dominante (âncora) não possui raiz local, com constituição } \\
\text { originária e sede principal em outra região do país. Ela mantém relações com } \\
\text { fornecedores, empresas e negócios em outras localidades, inclusive no } \\
\text { exterior. Este perfil implica em baixo crescimento endógeno na fase inicial, } \\
\text { mas pode ser considerado um multiplicador regional mediano dos efeitos } \\
\text { positivos para o crescimento do cluster. }\end{array}$ \\
\hline $\begin{array}{l}\text { Integração vertical e } \\
\text { cooperação }\end{array}$ & $\begin{array}{l}\text { A integração com os produtores é realizada a partir de contratos de } \\
\text { fornecimento exclusivo, de longo prazo. Para a manutenção de padrões, } \\
\text { acordados a priori por determinados mercados, a agroindústria promove } \\
\text { investimentos em instalações de aviários e introdução de técnicas modernas } \\
\text { nos integrados, com acompanhamento e treinamento contínuo. Essas ações } \\
\text { favorecem a construção da confiança e cooperação. }\end{array}$ \\
\hline $\begin{array}{l}\text { Especialização do } \\
\text { setor }\end{array}$ & $\begin{array}{l}\text { A maior parte das empresas (70\%) está habilitada para exportar, o que } \\
\text { reforça a característica de especialização no setor e mostradas pelos } \\
\text { indicadores } Q L(4,26) \text { e } G L(63 \%) \text {. }\end{array}$ \\
\hline $\begin{array}{c}\text { Especialização no } \\
\text { emprego }\end{array}$ & $\begin{array}{l}\text { O Brasil lidera a exportação mundial de carne de frango e é o terceiro maior } \\
\text { produtor. O Paraná lidera a produção com } 31 \% \text { do total da produção nacional } \\
\text { e } 29 \% \text { das exportações (ABPA, 2014). A região sudoeste obteve o maior índice } \\
\text { especialização no emprego referente à atividade de abate e preparo de aves } \\
\text { e pequenos animais, com } Q L=4,26 \text {. }\end{array}$ \\
\hline Eficiência coletiva & $\begin{array}{l}\text { A conjugação de economias externas locais e ação conjunta, existente na } \\
\text { região Sudoeste, mostra uma tendência para investimentos em novas } \\
\text { tecnologias, o que favorece a inovação no setor. Esta combinação de fatores } \\
\text { constitui no que Schmitz (1997) define por eficiência coletiva. }\end{array}$ \\
\hline
\end{tabular}

Fonte: dados da pesquisa (2015).

As condições empíricas das aglomerações produtivas para o abate e preparo do frango da Mesorregião Sudoeste Paranaense, aqui demonstradas, aproximam-se da tipologia de Cluster Radial Transnacional, conforme descrição no Quadro 1.

\section{CONSIDERAÇÕES FINAIS}

Este estudo buscou identificar a existência de especialização na atividade de abate e preparo da carne de frango no Paraná e descrever a sua tipologia. Com base nos estudos de Pinela Dalmás, Staduto e Willers (2007), foram calculados o QL e $G L$ para a atividade, em todas as regiões paranaenses. O resultado apontou maior especialização do emprego na região sudoeste, em relação ao desempenho das 
demais regiões em análise, o que difere do resultado encontrado em 2006, no qual a Mesorregião Oeste detinha a maior especialização do emprego na atividade.

Além dos resultados do QL e GL, uma característica adicional de especialização no setor foi identificada, que é a competência da maior parte das empresas estabelecidas na Mesorregião para atuarem no mercado internacional. A busca por essa inserção no mercado mundial e maior representatividade nas decisões de políticas públicas para o setor, são favorecidas por meio das associações de classe.

A atividade de abate e preparo da carne de frango foi capaz de criar economias incidentais e deliberadas apontadas por Suzigan et al. (2004), pois a forma de atuação adotada promove a ação conjunta na obtenção de vantagens competitivas. Isso ocorre por meio da abertura de novos mercados e de oportunidades de negócios, provocadas pela dinâmica do setor. A ação conjunta também foi observada no esforço para superar problemas referentes ao comércio internacional, principalmente aos inerentes à sanidade animal.

O efeito da conjugação das economias externas locais e da ação conjunta, ora descritas, desencadeia uma tendência para investimentos em novas tecnologias, o que permite a ocorrência de inovações. Esse processo faz parte do que Schmitz (1997) preconiza como eficiência coletiva.

$\mathrm{Na}$ região sudoeste do Paraná está presente um perfil industrial capitaneado por empresa de grande porte, que apresenta domínio e liderança no setor, entendida como a empresa âncora descrita por Markunsen (1995), na tipologia denominada de clusters radiais. As outras empresas que compõem a aglomeração produtiva são agroindústrias locais cooperativadas, que integram produtores, principalmente de pequeno porte, para o fornecimento do frango em condições de abate. Essa integração ocorre por meio de contratos de longo prazo, promovidos por investimentos para instalações de aviários e introdução de técnicas modernas, com acompanhamento e treinamento contínuo, que favorece um relacionamento de confiança e cooperação. Essas características estão presentes na descrição da tipologia de Markunsen (1995), denominada radial transnacional.

A dinâmica organizacional da empresa âncora indica a existência de um multiplicador regional mediano, dos efeitos positivos para o crescimento do cluster na atividade. Apesar disso, segundo dados do Sindiavipar (2015), 70\% das empresas que atuam no sudoeste paranaense estão habilitadas para a exportação. Além disso, a geração de empregos diretos da atividade indica uma participação acima da média, em relação ao desempenho do Estado ( $G L=63 \%$ ), o que representa a importância da atividade no aumento da renda na região.

Diante dos resultados é possível concluir que o aglomerado de indústrias de abate e preparo da carne de frango, localizado na região sudoeste paranaense, congrega evidências empíricas para ser considerado um cluster produtivo do tipo radial transnacional. No entanto, ainda são necessárias consultas por amostragem de empresas, que possam precisar as relações interfirmas originadas a partir dessa aglomeração produtiva.

Embora não seja a pretensão esgotar o tema, entende-se que os objetivos deste estudo foram atingidos e contribuições foram dadas. Porém, houve limitações no sentido de aprofundar a análise em relação à conjuntura internacional e o acesso aos seus mercados, assim como a identificação de variáveis que afetam o 
desempenho produtivo das regiões do Paraná. Portanto, o estudo não encerra aqui, mas abre oportunidades para trabalhos futuros.

\section{REFERÊNCIAS}

ALTENBURG, T.; STAMER, M. How to promote clusters: policy experiences from Latin America. World Development. Elsevier. v. 27. p. 1693-1713, sept. 1999.

AUDRETSCH, D. B.; FELDMAN, M. P. R. D. Sillovers and the geography of innovation. American Economic Review. vol. 86, n. 3, p. 630-640, jun. 1996.

BELUSSO, D.; HESPANHOL, A. N. A evolução da avicultura industrial brasileira e seus efeitos territoriais. Revista Percurso (Maringá), v.2, n. 1, p. 25-51, 2010.

BRF. Relatório Anual e de Sustentabilidade. 2014. 116 p. Disponível em: <http://www.brf-global.com/brasil/responsabilidade-corporativa/relatorio-anual>. Acesso em: 24 out. 2015.

DELGADO, A. P.; GODINHO, I. M. Medidas de localização das actividades e de especialização concepção de desenvolvimento regional. In: COSTA, J. S. (Coord.) Compendio de Economia Regional. Coimbra - PT: APDR, 2002.

DERAL - Departamento de Economia Rural. Secretaria de Estado da Agricultura e do Abastecimento do Paraná. Valor bruto da produção. 2014. Disponível em: < http://www.agricultura.pr.gov.br/modules/conteudo/conteudo.php?conteudo=156>. Acesso em 30 ago. 2015.

HADDAD, P. R. Medidas de Localização e de Especialização. In: HADDAD, P. R (Coord.). Economia Regional: Teorias e Métodos de Análise. Banco do Nordeste do Brasil S.A. Fortaleza, 1989, p. 225-248.

IEA - Instituto de Economia Agrícola. Secretaria de Agricultura e Abastecimento do Estado de São Paulo. Perspectivas da Carne de Frango no Estado de São Paulo em 2015. Texto de Maximiliano Miura. 18 jun. 2015. Disponível em: http://www.iea.sp.gov.br/out/LerTexto.php?codTexto=13705>. Acesso em 03 out. 2015.

IGLIORI, Danilo Camargo. Economia dos clusters industriais e desenvolvimento. São Paulo: Iglu: FAPESP, 2001, 147 p.

IPARDES - Instituto Paranaense de Desenvolvimento Econômico e Social. Arranjos produtivos locais e o novo padrão de especialização regional da indústria paranaense na década de 90. Curitiba: IPARDES, 2003, 95 p.

. Instituto Paranaense de Desenvolvimento Econômico e Social - IPARDES. Mapas. Base Física e Política. Relação dos municípios por microrregiões e mesorregiões geográficas - Paraná. Disponível em <www.Ipardes.gov.br >. Acesso em: 24 ago 2015. 
Perfil da região geográfica Sudoeste paranaense. Disponível em: <http://www.ipardes.gov.br/perfil_municipal>. Acesso em: 25 out. 2015.

KRUGMAN, P. Geography and trade. Cambridge, MA: MIT Press, 1991.

MARKUSEN, A. Áreas de atração de investimento em um espaço econômico cambiante: uma tipologia de distritos industriais. In: Revista Nova Economia. Belo Horizonte: UFMG. v.5, n.2, dez. 1995, p.9-44.

MINISTÉRIO DO DESENVOLVIMENTO. Secretaria de Comércio Exterior. Estatística de comércio exterior. Balança Comercial Brasileira: mensal. Dezembro 2014. Exportação. Grupo de produtos: acumulados e mensal. Disponível em: <http://www.mdic.gov.br//sitio/interna/interna.php?area=5\&menu=4861\&refr=1161>. Acesso em: 25 out. 2015.

MINISTÉRIO DO TRABALHO E EMPREGO - MTE. Brasil. Dados estatísticos. PDET. Acesso on line às bases estatísticas RAIS e CAGED. 2014. Disponível em: <http://bi.mte.gov.br/bgcaged/caged_rais_vinculo_id/login.php>. Acesso em 03 out. 2015.

MITELKA, L.; FARINELLI, F. Local clusters, innovations systems and sustained competitiveness. Nota Técnica $n^{\circ} 5$ do Projeto: Arranjos e sistemas produtivos locais e as novas políticas de desenvolvimento industrial e tecnológico. Rio de Janeiro: IE/UFRJ/BNDES/FINEP/FUJB, 2000.

PAULA, S. R. L., FILHO, P. F. Exportações de carne de Frango. BNDES Setorial, Rio de Janeiro, n. 17, p. 93-108, mar. 2003.

PINELA DALMÁS, S. R. S.; STADUTO, J. A. R.; WILLERS, E. M. A Identificação de Cluster na Atividade de Abate de Frangos na Mesorregião Oeste do Paraná. Grupo de Pesquisa 2 - Administração Rural e Gestão do Agronegócio. In.: XLV CONGRESSO DA SOBER. Anais ... Londrina, PR, 22 a 25 jul. 2007.

PORTER, M.E. Clusters and the new economics of competition. Harvard Business Review, Nov/Dec, 1998.

RISSETE, C.; MACEDO, M.M.; MEINERS, W.E.M.A. Identificação e tipologia de clusters da região metropolitana de Curitiba. In.: II ENCONTRO DE ECONOMIA PARANAENSE - ECOPAR. Anais ... Maringá: UEM-UEL-UEPG-UNIOESTE-IPARDES, 2003, p. 357-378.

SANTOS, F.; GROCCO, M.; LEMOS, M. Arranjos e sistemas produtivos locais em "espaços industriais" periféricos: estudo comparativo de dois casos brasileiros. Revista de economia contemporânea. Rio de Janeiro, v.6, n.2, p. 147-180, jul./dez. 2002. 
SCHMITZ, H. Collective efficiency and increasing returns. Brighton: IDS Working Paper 50, 1997.

SCHUMPETER, J. A. The theory of economic development. Cambridge: Harvard University Press, 1934.

SIFFERT FILHO, Nelson; FAVERET FILHO, Paulo. O Sistema Agroindustrial de Carnes: Competitividades e Estruturas de Governança. Versão modificada de trabalho apresentado no Seminário sobre Competitividade na Indústria de Alimentos, Campinas: ITAL. 15 a 16 de abril de 1998.

SINDIAVIPAR - SINDICATO E ASSOCIAÇÃO DOS ABATEDOUROS E PRODUTORES AVÍCOLAS DO PARANÁ. Abatedouros. 2015. Disponível em $<w w w . s i n d i a v i p a r . c o m . b r>$. Acesso em 19set. 2015.

STADUTO, J. A. R.; FERRERA DE LIMA, J.; STAMM, C.; MALDANER, I. S. Análise locacional das ocupações nas regiões metropolitanas e não-metropolitanas do estado do Paraná. Revista de Economia (Curitiba), v. 34, p. 117-139, 2008.

STAMER, J. M. Estratégias de desenvolvimento local e regional:Clusters, políticas de localização e competitividade sistêmica. Joinville: Fundação Empreender, 2000.

SUZIGAN, W.; FURTADO, J.; GARCIA, R.; SAMPAIO, S. E. K. Clusters ou sistemas locais de produção. Mapeamento, tipologia e sugestões de políticas. Revista de Economia Política, São Paulo: Centro de Economia Política, v.24, n. 4, out./dez. 2004, p. 543-562.

TRICHES, D.; SIMAN, R. F.; CALDART, W. L. A cadeia produtiva da carne de frango da região da Serra Gaúcha: uma análise da estrutura de produção e mercado. Artigo do Projeto de pesquisa do IPES/UCS. Versão 15 set 2004. Disponível em:

<https://www.ucs.br/site/midia/arquivos/IPES_TS_011_SET_2004.pdf >. Acesso em: 25 set. 2015.

UBABEF - UNIÃO BRASILEIRA DE AVICULTURA. Relatório Anual 2012. Disponível em <http://abpa-br.com.br/setores/avicultura/publicacoes/relatorios-anuais >. Acesso em 25 set. 2015.

. Relatório Anual 2014. Disponível em <http://abpa-

br.com.br/setores/avicultura/publicacoes/relatorios-anuais>. Acesso em 25 set. 2015.

UNCTAD - UNITED NATIONAL CONFERENCE ON TRADE DEVELOPMENT. Promoting and sustaining SMEs clusters and networks for development. Commission on Enterprise. Business Facilitation and Development. Geneva, September, 1998. 
Jefferson Andronio Ramundo Staduto. Doutor em Ciências (Economia Aplicada) pela Universidade de São Paulo. Professor associado da Unioeste/Campus Toledo, Departamento de Economia, na área de desenvolvimento rural, agronegócio, desenvolvimento regional, mercado de trabalho e Paraná, inovação agroindustrial. jstaduto@yahoo.com.br

Sandra Regina da Silva Pinela. Doutoranda e Mestre em Desenvolvimento Regional e Agronegócio da Universidade Estadual do Oeste do Paraná, com estágio na Universidade de La Rioja, Espanha. Professora Adjunto da UTFPR/Campus Toledo, do Núcleo de Ciências Humanas, Letras e Sociais Aplicadas, área de Administração. sandrarspinela@gmail.com

Ednilse Maria Willers. Doutora e Mestre em Desenvolvimento Regional e Agronegócio pela Universidade Estadual do Oeste do Paraná/Toledo. Professora do Curso de Secretariado Executivo da Universidade Estadual do Oeste do Paraná/Toledo, áreas de Secretariado Executivo e de Economia Regional.ednilse26@yahoo.com.br 